\title{
Extent of Left Atrial Enlargement in Rheumatic Mitral Valve Disease
}

Rajeev Merwaha, Kunal Mahajan*, Sachin Sondhi and Shivani Rao

Department of Cardiology, Indira Gandhi Medical College, India

Keywords: Giant left atrium; Rheumatic mitral valve disease; Echocardiography

\section{Introduction}

A 38-year-old male, under evaluation for dyspnea, was referred to us for echocardiography. On performing cardiovascular examination, he was having a grade III pan-systolic murmur at the apex which was radiating to the axilla. A long mid diastolic rumbling murmur was also heard with pre-systolic accentuation and an opening snap. His Chest X-ray showed cardiomegaly with marked left atrial enlargement, causing opacification of the right lower lung zone (Figure 1A). Echocardiography was done which revealed a markedly dilated left atrium with an antero-posterior diameter of $108 \mathrm{~mm}$ in parasternal long axis view (Figure 1B). Mitral valve leaflets were thick, calcified and showed restricted movement (Figure 1C). Mitral stenosis was moderate with a valve area of $1.3 \mathrm{~cm}^{2}$. Severe mitral regurgitation was also present along with mild aortic regurgitation and mild tricuspid regurgitation. Computed tomography scan revealed the true extent of left atrial enlargement with dimensions of $200 \times 110 \times 168 \mathrm{~mm}$ (Figures $1 \mathrm{D}$ and $1 \mathrm{E}$ ). This makes it one of the largest left atrium ever reported in the literature. Patient was subjected to mitral valve replacement. This case highlights the extent of enlargement a left atrium can undergo in rheumatic mitral valve disease. Direct involvement of left atrial tissue by rheumatic process in addition to increased hemodynamic load imposed by mitral stenosis and regurgitation are the possible mechanisms [1].

\section{References}

1. Loch A, Sadiq MA, Wan AWA (2013) Giant left atrium in a patient with prosthetic mitral valve. Eur Heart J 34: 981.
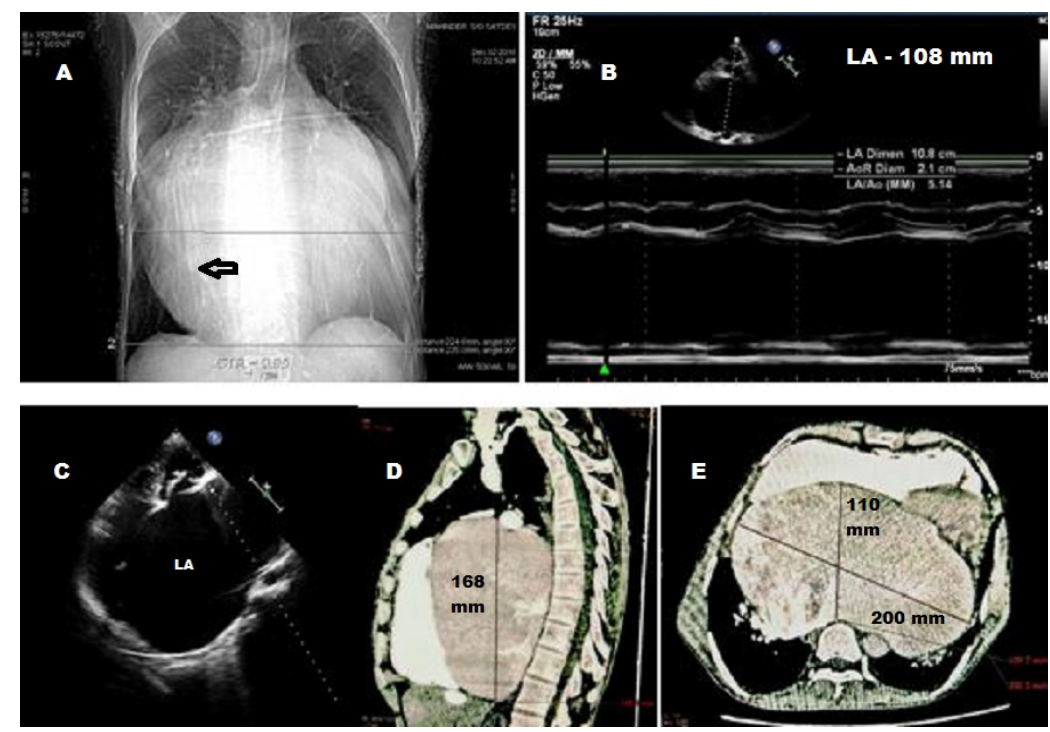

Figure 1: (A) Chest X-Ray showing an enlarged left atrium with double- density sign. Note the left atrial border (arrow) causing opacification of right lower lung. (B) Transthoracic echocardiogram -parasternal long axis view showing a giant left atrium. (C) Apical -4- chamber view showing an enlarged left atrium . Note the doming, thickened mitral valve leaflets. (D) CT Thorax showing superior-inferior extent of the left atrium. (E) CT Thorax-axial view- showing a massively enlarged left atrium.

Received February 08, 2017; Accepted February 09, 2017; Published February 20, 2017

Citation: Merwaha R, Mahajan K, Sondhi S, Rao S (2017) Extent of Left Atrial Enlargement in Rheumatic Mitral Valve Disease. J Cardiovasc Dis Diagn 5: i105. doi: 10.4172/2329-9517.1000i105

Copyright: (c) 2017 Merwaha R, et al. This is an open-access article distributed under the terms of the Creative Commons Attribution License, which permits unrestricted use, distribution, and reproduction in any medium, provided the original author and source are credited. 